\title{
PRODUCTION AND FUNDAMENTAL VALIDATION OF GLOBAL SURFACE WATER MAP USING MULTIPLE MICROWAVE RADIOMETERS
}

\author{
Shinta $\mathrm{SETO}^{1}$ and Hironori MINE${ }^{2}$ \\ ${ }^{1}$ Member of JSCE, Associate Professor, Graduate School of Engineering, Nagasaki University \\ (Bunkyo-machi 1-14, Nagasaki-shi, Nagasaki 852-8521, Japan) \\ E-mail: seto@nagasaki-u.ac.jp (Corresponding Author) \\ ${ }^{2}$ Non member, Graduate School of Engineering, Nagasaki University (ditto)
}

\begin{abstract}
Information of surface water is necessary for flood disaster mitigation and the hydrological cycle studies. Normalized Differential Frequency Index (NDFI) was calculated by multiple microwave radiometers GMI and AMSR2 to produce a daily and 0.1-degree global surface water map for five years (2013-2017). Diurnal variation and bias between sensors in NDFI were adjusted. The basic performance of the surface water map was tested with global datasets. The five-year average NDFI and inundation ratio by Global Surface Water showed very high correlation around Japan. Monthly variation in NDFI and inundation ratio by Yesterday's Earth at EORC showed positive correlation along some large river channels. NDFI showed a sudden increase at daily scale in some dry areas where daily variation in NDFI and antecedent precipitation index had positive correlation. These indicate that the increase in NDFI could be caused by inland water inundation rather than flood inundation.
\end{abstract}

Key Words: surface water, microwave radiometer, inundation, antecedent precipitation index, GSMaP

\section{INTRODUCTION}

Information on inundation of river and overland flooding is necessary to assess the damage to property and to undertake mitigation measures during a heavy rainfall event. In addition, changes in the surface area of land and water due to different land use activities, such as rice paddies and reservoirs, affect the hydrological cycle through evaporation and runoff processes.

Takeuchi et al. ${ }^{1)}$ calculated the normalized differential frequency index (NDFI) from the observed brightness temperature of the microwave radiometer, advanced microwave scanning radiometer for Earth Observing System (EOS), AMSR-E, onboard the Aqua satellite. It was used as an index to estimate ground surface covered by water (hereinafter, surface water). Surface water can have natural origins, such as that caused by flood inundation, and anthropogenic sources, such as rice paddies and reservoirs. In this study, we calculated the NDFI for surface water index from brightness temperatures acquired by multiple microwave radiometers operated by the global precipitation measurement (GPM) mission ${ }^{2)}$, and produced daily global surface water maps for five years from 2013 to 2017 on a $0.1^{\circ}$ grid.

Existing products for surface water assessment include global inundation extent from multi-satellites (GIEMS) with a monthly temporal resolution and a grid of $0.25^{\circ}$. It uses visible, infrared, and microwave sensors and was recently downscaled to a $90 \mathrm{~m}$ grid using elevation data (GIEMS-3D) ${ }^{3)}$. Pekel et al. ${ }^{4)}$ developed the global surface water (GSW) using LANDSAT observations of over 30 years, which included the frequency of water coverage on a $30 \mathrm{~m}$ grid. Thus, the existing products have excellent spatial resolution, but lack high temporal resolution. This study is unique owing to the development of a product designed to determine the increase in surface water with the temporal resolution for a few days, which may indicate the possibility of water-related disasters.

Cross-calibrated brightness temperature data from multiple microwave radiometers operated under the GPM have been published ${ }^{5}$. In this study, we used brightness temperature data from the microwave radiometer, GPM microwave imager (GMI), onboard the main satellite of the GPM, and AMSR2 onboard 
the global change observation mission-water (GCOM-W) satellite, which have channels with frequencies of 18.7 and $23.8 \mathrm{GHz}$. These frequencies are necessary to calculate the NDFI. Precipitation and cloud cover do not severely affect NDFI calculation because it uses a relatively low-frequency brightness temperature; but since heavy rainfall can affect the performance, future corrections in this context are necessary.

Global precipitation maps, such as global satellite mapping of precipitation (GSMaP $)^{6}$, have been produced as part of GPM. The Japanese Aerospace Exploration Agency (JAXA) and the University of Tokyo have developed Yesterday's Earth at EORC $(\mathrm{YEE})^{7), 8)}$, a land surface and river inundation simulation, which also uses GSMaP as input, to calculate the inundation area ratio and other factors. The combination of the surface water indices estimated in this study along with the precipitation data, such as GSMaP, will provide a multifaceted understanding of the hydrological cycle.

This paper is structured as follows: In section 2, we explain the development procedure of the global surface water map, and from sections 3 to 5 , we present the fundamental validation results of the surface water map using global data. Finally, section 6 provides a summary of the entire study and discusses the future perspectives.

\section{DEVELOPMENT OF GLOBAL SUR- FACE WATER MAP}

\section{(1) Brightness temperature data from micro- wave radiometer}

The brightness temperature data of GMI and AMSR2 in the level $1 \mathrm{C}$ product (L1C) of GPM were used. The level 1B product included the brightness temperature by sensor-specific calibration, while the brightness temperature of L1C was calibrated to reduce the bias between sensors. The product version used in this study was 05A. GMI and AMSR2 data have been available since March 2014 and July 2012, respectively. We used the 2013 - 2017 data for this study.

We acquired the brightness temperature of 18.7 $\mathrm{GHz}$ vertical polarization (TB18.7V), $23.8 \mathrm{GHz}$ vertical polarization (TB23.8V), and the center position (latitude and longitude) at each footprint. To simplify the calculations and assessments, the observation time was represented by the observation start time of the orbit. A difference of less than approximately $90 \mathrm{~min}$ with respect to the observation time of footprints was observed, but this did not interfere with the data development in units of days.

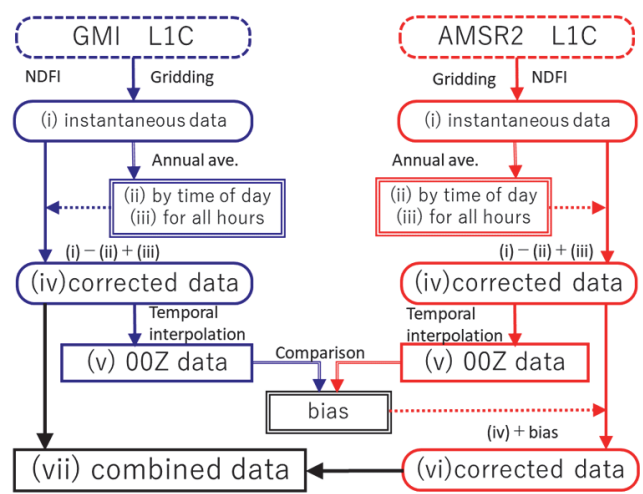

Fig.1 Development procedure of Global Surface Water map.

\section{(2) Development procedure}

The procedure for developing the global surface water map is shown in Fig.1. Initially, the NDFI for each footprint was calculated using Equation (1):

$$
\mathrm{NDFI}=\frac{\mathrm{TB}(23.8 \mathrm{~V})-\mathrm{TB}(18.7 \mathrm{~V})}{\mathrm{TB}(23.8 \mathrm{~V})+\mathrm{TB}(18.7 \mathrm{~V})}
$$

The above NDFI values were assigned to the $0.1^{\circ}$ grid, which contained the center position of the footprint [instantaneous data, (i)].

The data of (i) were aggregated and averaged for each sensor, year, and time of day (hourly from $00 \mathrm{Z}$ to 23Z) [Average data by time of day for each sensor and year, (ii)]. In addition, average data regardless of time of day were calculated [Average data for each sensor and year, (iii)].

The diurnal variation in the data at $X Z$ was corrected by value of (i) - the average data value at $X Z$ of (ii) + the annual average value of (iii) [diurnal variation-corrected instantaneous data, (iv)].

For each sensor, (iv) was time-interpolated to acquire the value at midnight for each day. Linear interpolation was conducted using the data at the closest time before and after the interpolation target time [data at $00 \mathrm{Z}$ by sensor, (v)].

The AMSR (v) data were compared with GMI (v) data to get the annual bias. The resulting bias was then added to (iv) of AMSR2 and adjusted according to the GMI standard [instantaneous data corrected for diurnal variation and inter-sensor bias, (vi)]. Note that AMSR2 data beyond the GMI observation range (above approximately $70^{\circ}$ latitude) were not corrected. Furthermore, we used the 2015 bias values for 2013.

The daily $00 \mathrm{Z}$ value was obtained from (iv) of GMI and (vi) of AMSR2. Regardless of the sensor, the value was linearly interpolated using the data at the nearest time before and after the interpolation target time [data at $00 \mathrm{Z}$ by sensor composite, (vii)].

Temporal and spatial data of (vii) were averaged wherever necessary. 


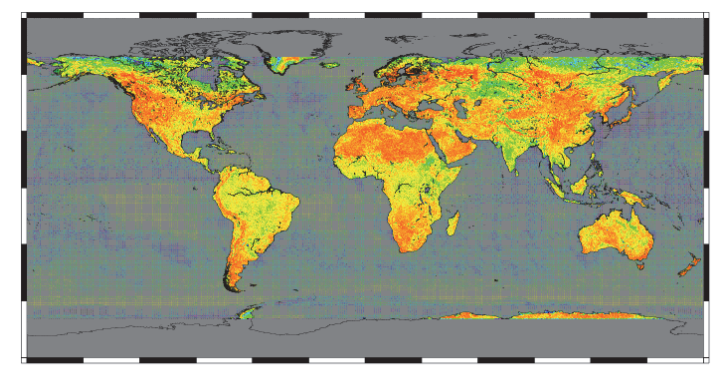

Fig.2 Diurnal variation range of NDFI for GMI in 2015 .

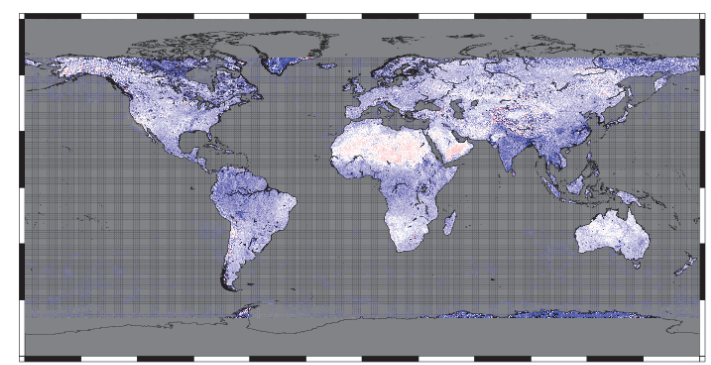

Fig.3 Anomaly in NDFI for GMI from NDFI for AMSR2 in 2015.

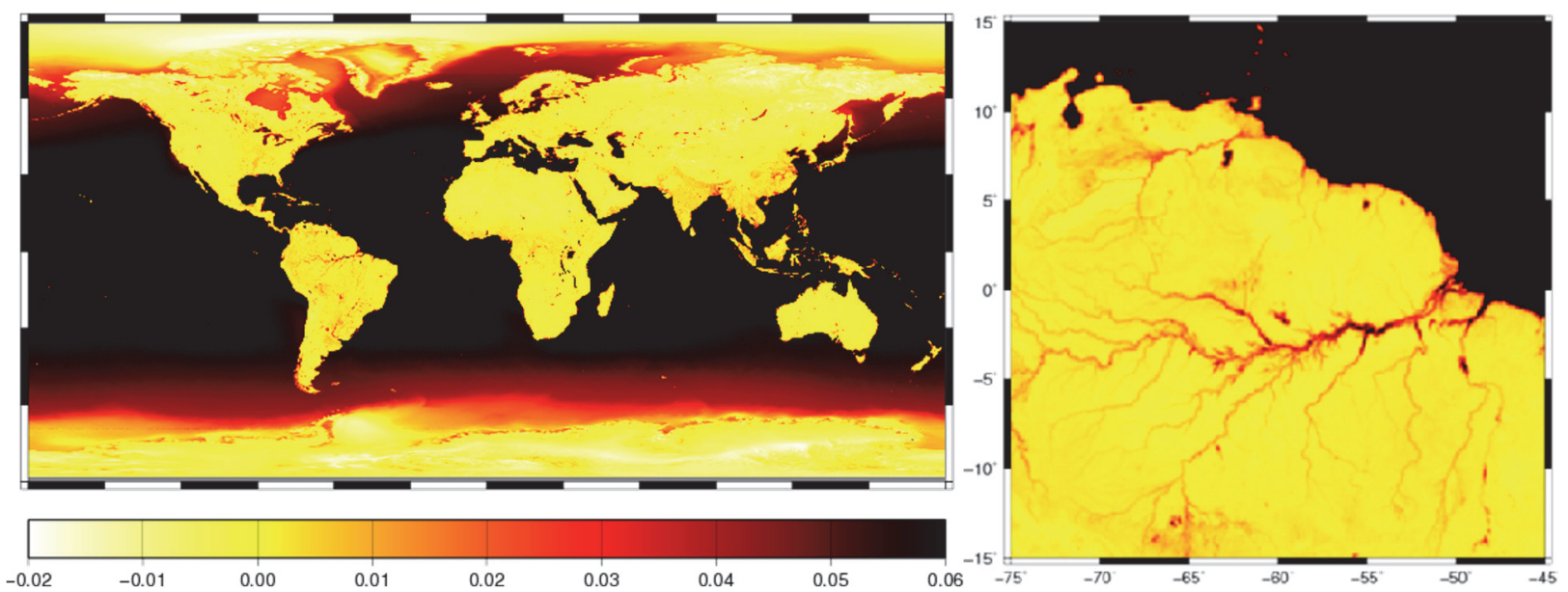

Fig.4 Five-year average of NDFI for the period from 2013 to 2017 . Right figure shows the area around Amazon River basin.

\section{(3) Need for correction}

Here, we explain the need for diurnal variation correction and bias correction between sensors conducted during the development procedure.

Figure 2 shows the diurnal range of variability for GMI in 2015; the minimum NDFI value by time was subtracted from the maximum NDFI value by time and the resultant highest value was approximately 0.01 . In arid regions, the diurnal variation was low at approximately 0.002 . The values at night were observed to be higher than those during daytime. Since diurnal variation was relatively large, correction was necessary.

Figure 3 shows the bias for 2015, which was acquired by subtracting the annual average NDFI of AMSR2 from the annual average NDFI of GMI. The resultant value was positive in most of the land areas, with a maximum value of approximately 0.002 . It was even smaller in arid regions. Although the bias between sensors was small since L1C was used, it was corrected to remove uncertainty.

\section{SPATIAL DISTRIBUTION OF NDFI AND WATER COVERAGE RATIO}

\section{(1) Spatial distribution of NDFI}

Figure 4 shows the spatial distribution of the five- year average of the NDFI for (vii) acquired in the previous section for the period $2013-2017$. The mean values of NDFI are in the range from -0.02 to 0.06 on land, and 0.06 or above in the ocean excluding the high latitude zone. An enlarged area of the Amazon River is shown on the right side of Fig.4. In terrestrial areas, places with high NDFI were observed along the channels of large rivers.

\section{(2) GSW water coverage}

GSW was used to quantitatively evaluate the spatial distribution of NDFI. GSW has a high spatial resolution of $0.00025^{\circ}$ (approximately $30 \mathrm{~m}$ ) grid. However, since the observational frequency of LANDSAT was low, the water coverage frequency (ratio of the number of times the area was covered by water to the total number of observations) and other data were acquired as statistics throughout the observation period (1984 - 2015) and not as time series data. Here, we made a comparison without considering the difference in the times that NDFI and GSW covered, i.e., the change over time. The spatially averaged value of the water coverage frequency is called the water coverage ratio.

\section{(3) Evaluation}

Water coverage ratio corresponding to the $0.1^{\circ}$ grid was calculated in accordance with NDFI. 

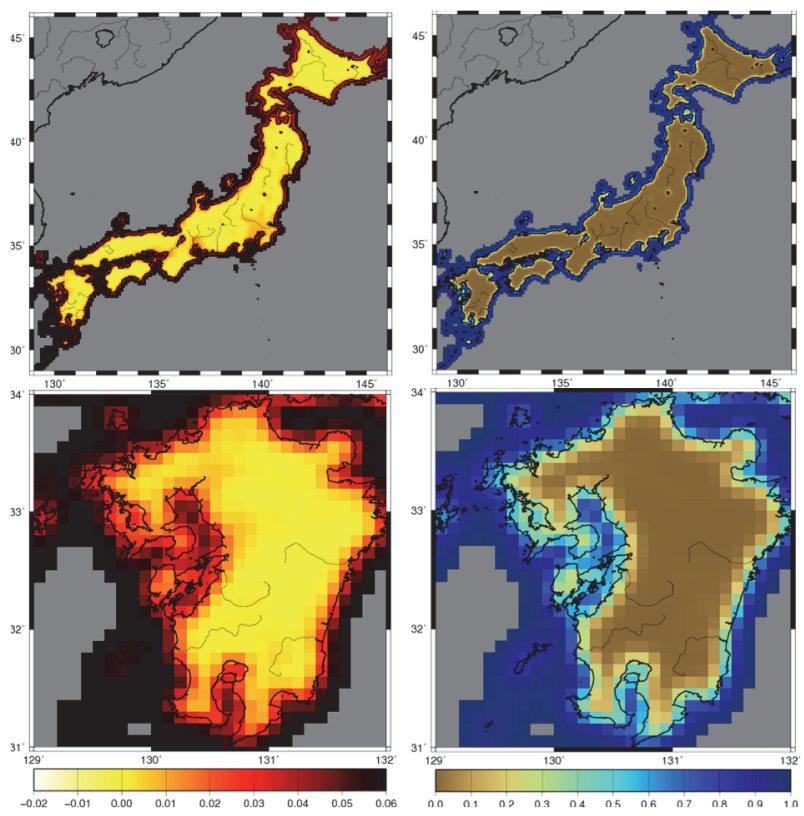

Fig.5 (left) NDFI and (right) water cover ratio around (top) Japan and (bottom) Kyusyu Island. Gray area is out of the analysis.

However, after considering the resolution of the microwave radiometer, the $0.1^{\circ}$ grid NDFI data included influence from beyond the grid. Therefore, the $0.1^{\circ}$ water coverage ratio was calculated as follows:

First, the GSW water coverage frequency was averaged and corrected to a value of $0.01^{\circ}$ grid (denoted as $w$ ). Next, we assumed that for each of the hundred $0.01^{\circ}$ squares within the $0.1^{\circ}$ grid, there was a footprint center of the microwave radiometer. We took a $41 \times 410.01^{\circ}$ grid centered on a $0.01^{\circ}$ pixel. The weighted average of $w$ was taken by considering the antenna pattern. The nominal values ${ }^{2), 9)}$ were 14 $\mathrm{km}(\mathrm{CR}$ : cross track direction $) \times 22 \mathrm{~km}(\mathrm{AR}$ : along track direction) at $18.7 \mathrm{GHz}$, and $15 \mathrm{~km}(\mathrm{CR}) \times 26$ $\mathrm{km}(\mathrm{AR})$ at $23.8 \mathrm{GHz}$ for the AMSR2 footprint, and $11.2 \mathrm{~km}(\mathrm{CR}) \times 18.3 \mathrm{~km}(\mathrm{AR})$ at $18.7 \mathrm{GHz}$, and 9.2 $\mathrm{km}(\mathrm{CR}) \times 15.0 \mathrm{~km}(\mathrm{AR})$ at $23.8 \mathrm{GHz}$ for the GMI footprint. However, it was difficult to consider the direction of the antennas at this stage; thus, the antenna pattern was assumed to be Gaussian and directionality was not taken into account. The water coverage ratio $W$ for a $0.01^{\circ}$ square $(I, J)$ was then obtained from Equation (2):

$$
\begin{aligned}
& \sum_{j=-20}^{20}\left\{\sum_{i=-20}^{20} w(I+i, J+j) \exp \left(-\frac{i^{2}+j^{2}}{N^{2}}\right)\right\} \\
& \sum_{j=-20}^{20}\left\{\sum_{i=-20}^{20} \exp \left(-\frac{i^{2}+j^{2}}{N^{2}}\right)\right\}
\end{aligned}
$$

Since it was difficult to estimate the specific footprint size due to the combination of multiple sensors and frequencies, we tried using $N$ values from 1 to 20 .

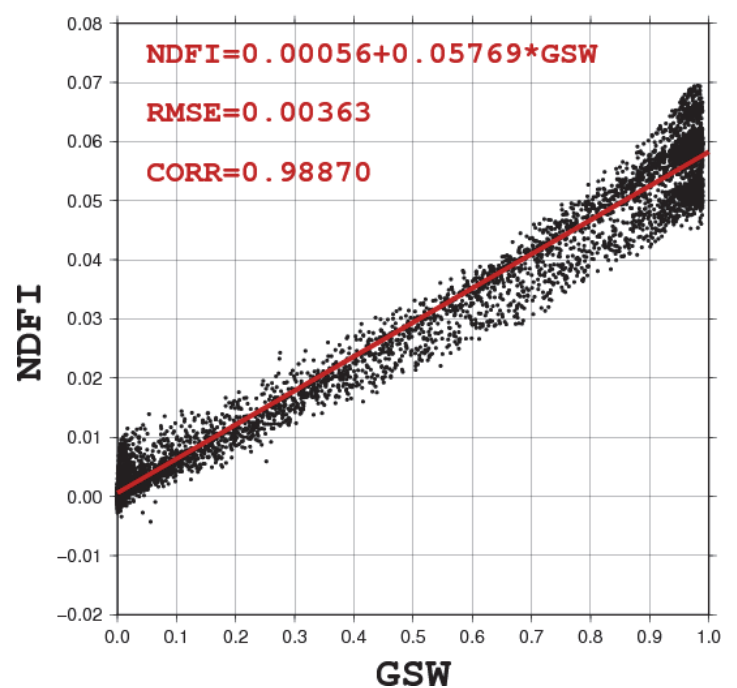

Fig.6 The relationship between water coverage ratio (GSW) and NDFI around Japan.

Finally, the calculated $W$ of the $0.01^{\circ}$ squares were averaged to give the water coverage ratio on the $0.1^{\circ}$ grid.

The evaluation was conducted in an area near Japan, where the water coverage ratio was less than 0.99 (Fig.5). The enlarged Kyushu region in the figure shows that the grids near the coastline were affected by the surrounding sea surface even when the majority of grids covered land.

The correlation coefficient between NDFI and water coverage ratio was highest for $N=10$, which corresponded to approximately $10 \mathrm{~km}$ and was marginally lower than the nominal value. Figure 6 represents a scatter plot of NDFI and water coverage ratio $(N=10)$ of the areas near Japan. A high positive correlation coefficient of 0.98870 was observed and the regression line was as follows:

$$
\mathrm{NDFI}=0.00056+0.05769 \mathrm{~W}
$$

\section{MONTHLY TEMPORAL VARIATION IN NDFI AND INUNDATION AREA RATIO}

\section{(1) Inundation area ratio}

YEE, which was developed by JAXA and the University of Tokyo, is a hydrological cycle simulation based on land surface (MATSIRO ${ }^{7)}$ ) and river routing and inundation $\left(\mathrm{CaMa}-\mathrm{Flood}^{8)}\right)$ models using reanalysis data (JRA-55) and satellite observation products (GSMaP and MODIS) as input. Subsequent data have been released sequentially since March 2018. In this study, the monthly inundation area ratios from 2013 to 2017 using the JRA-55 data as input were compared with the temporal variability of the NDFI. To equalize with the YEE inundation area ratio, the resolution of the 
global surface water map was divided from $0.1^{\circ}$ to $0.05^{\circ}$ and then averaged to $0.25^{\circ}$.

\section{(2) Results for major river basins}

Correlation coefficients between the temporal variation in the NDFI and inundation area ratio were determined for sites with a maximum inundation area ratio greater than 0.1 .

High correlation was observed along the river channel for the Amazon River [Fig.7 (a)]. Figure 8 (a) shows the temporal variation in the lower Amazon River (56.125W, 2.125S). The vertical axis of the plot was adjusted by $(\mathrm{NDFI})=($ inundation area ratio) $\times 0.06$ according to the results in section 3 . Contrastingly, the correlation was low in some areas of the upper Amazon River basin. Figure 8 (b) shows the temporal variation at $66.375 \mathrm{~W}, 3.875 \mathrm{~S}$. Seasonal variations were observed in the inundation area ratio, but the variation in NDFI was very low. This could be due to the difficulty in observing the water surface with a microwave radiometer since the river channel was covered by vegetation in the upstream region.

High correlation was observed in the upper reaches of the Mississippi River [Fig.7 (b)], but the correlation was poor in the lower reaches. Figure 8 (c) shows the temporal variation in the inundation area ratio in the lower reaches of Mississippi River $(91.125 \mathrm{~W}, 32.375 \mathrm{~N})$. The temporal variations in the NDFI and inundation area ratio were negatively correlated. This could be because YEE did not represent the flow control by dams and inundation deterrence by levees in the Mississippi River.

The correlation was high in Southeast Asia, especially in the lower reaches of large rivers, such as the Mekong River [Fig.7 (c)]. Figure 8 (d) shows the temporal variations in the lower reaches of the Mekong River (104.875E, 11.875N). The seasonal variations in NDFI and inundation area ratios show a good correlation, but the temporal variations in NDFI showed a relatively small peak in 2015. Conversely, the inundation area ratio did not change significantly over the years. Figure 8 (e) shows the temporal variation for Chao Phraya River (99.875E, 16.875N). NDFI was higher in 2017 than in previous years.

In Japan, the inundation area ratio exceeded 0.1 in some regions [Fig.7 (d)]. Figure 8 (f) shows the temporal variation in the Chikugo River basin $(130.375 \mathrm{E}, 33.375 \mathrm{~N})$. An increasing trend in these two factors was observed in summer.

As described above, a good correlation between the temporal variability in NDFI and inundation area ratio was observed for multiple regions, but the absolute values and the range of variability vary in different regions. Considering the characteristics of NDFI and YEE, future research should include regional verifications of these relationships,

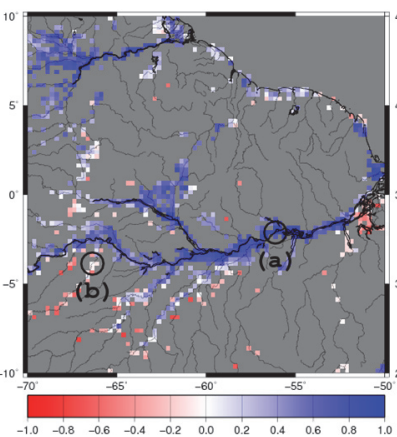

(a) Amazon River basin

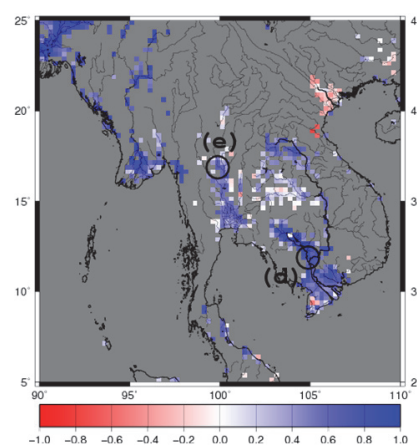

(c) Southeast Asia

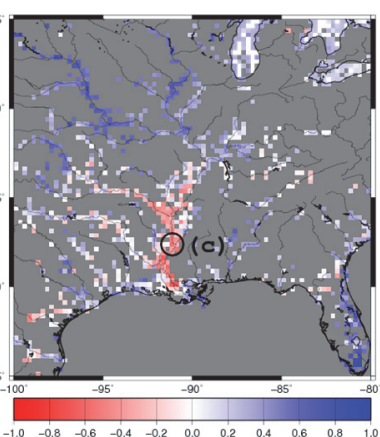

(b) Mississippi River basin

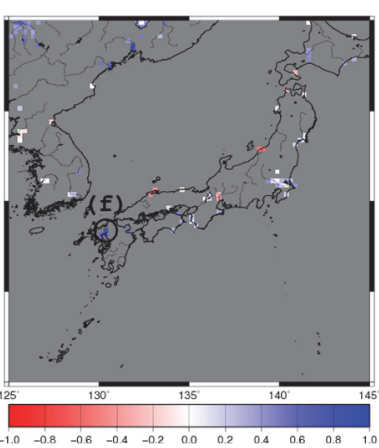

(d) Japan
Fig.7 Monthly temporal correlation coefficients between NDFI and inundation area ratio (YEE). Gray area is out of the analysis as the maximum value of inundation area ratio is lower than 0.1 .

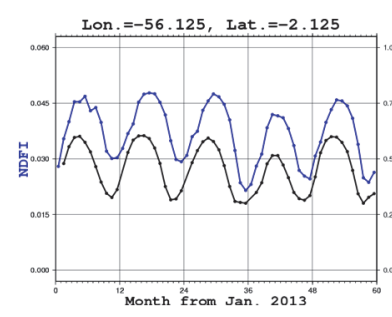

(a) Lower Amazon River

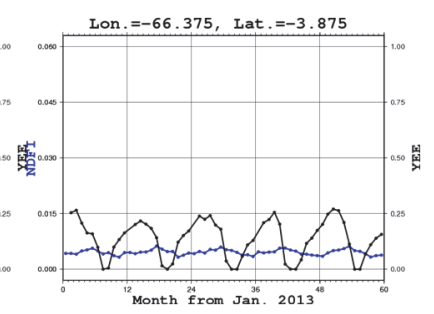

(b) Upper Amazon River

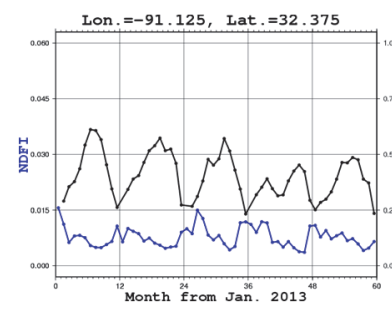

(c) Lower Mississippi River

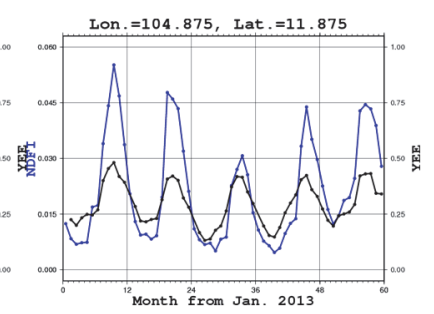

(d) Lower Mekong River

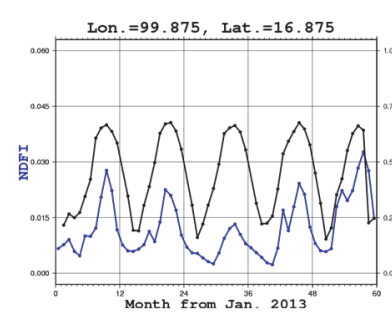

(e) Chaophraya River

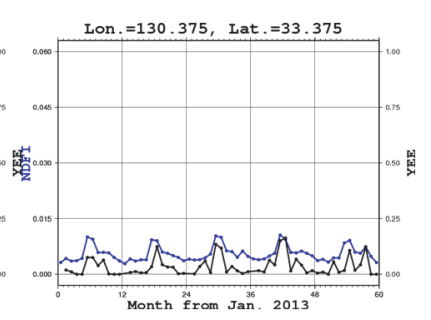

(f) Chikugo River
Fig.8 Monthly time series of NDFI (blue) and inundation area ratio (YEE; black) for six points shown in Fig. 7. 
quantification of the relationship between them, and the development of integrated surface water information.

\section{DAILY TEMPORAL VARIATION IN NDFI}

\section{(1) Assessment of sudden increases in NDFI}

A significant increase in NDFI within a few days indicates the occurrence of a water-related disaster. We developed an index to examine these sudden increases in NDFI. To assess the daily NDFI, $\triangle$ NDFI represents the final value after subtracting the maximum NDFI value of the previous three days from the NDFI value of each day. $\triangle$ NDFI for each day and its maximum value $\left(\Delta \mathrm{NDFI}_{\max }\right)$ was calculated during $2013-2017$. However, $\Delta$ NDFI $_{\max }$ was uniformly high near the coast. The mean of the absolute value of the difference between the NDFI of the day and the day before was defined as $|\Delta \mathrm{NDFI}|_{\text {ave, }}$ and the D-NDFI acquired using the formula given below represented the index for the sudden increase in NDFI.

$$
\mathrm{D}-\mathrm{NDFI}=\frac{\Delta \mathrm{NDFI}_{\max }}{|\Delta \mathrm{NDFI}|_{\text {ave }}}
$$

The distribution of D-NDFI is shown in Fig.9. High D-NDFI values were prevalent in the arid regions of the Middle East, Sahel, and Australia. Conversely, D-NDFI was low in large river basins, such as the Amazon River. Locations with such sudden increases in daily NDFI were different from the locations with a pronounced seasonal variation in NDFI in response to flood inundation. A sudden increase in NDFI usually represents overland flooding rather than river flooding.

\section{(2) Antecedent precipitation index (API)}

API was used as an indicator for overland water. For precipitation data, we used GSMaP reanalysis and standard product version 6 . The data were converted to daily precipitation according to the NDFI temporal resolution. The API was calculated by the following equation:

$$
\operatorname{API}_{d}(r)=\sum_{i=0}^{\infty} P_{d-i} r^{i}
$$

where $P$ is the daily precipitation, and the subscript is the number of days. We used a range of $r$ from 0.1 to 0.9 with increments of 0.1 . API results for $r=0.5$ are presented in the following section.

\section{(3) Correlation between NDFI and API}

The correlation coefficients for daily temporal variations between NDFI and API $(r=0.5)$ are shown in Fig.10. However, due to GSMaP data limitations,

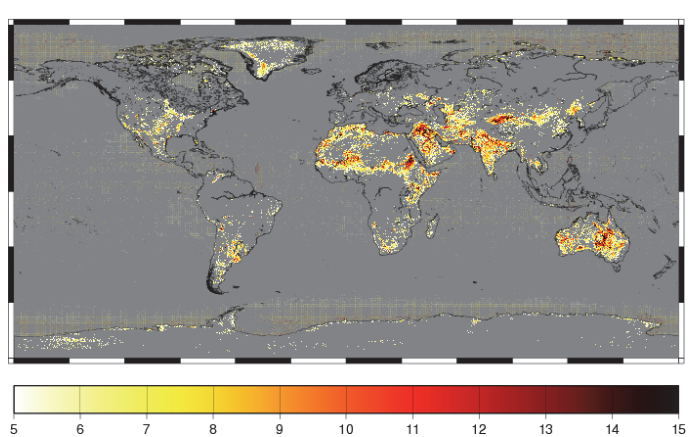

Fig.9 Distribution of D-NDFI (masked if D-NDFI is less than 5).

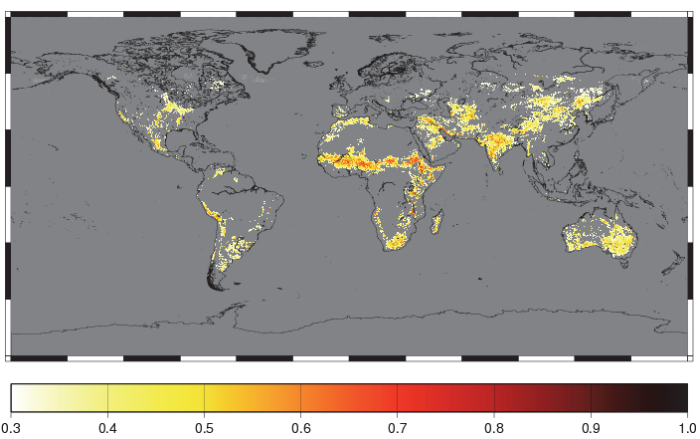

Fig.10 Correlation coefficients between NDFI and API $(r=0.5)$ (masked if the coefficient is lower than 0.3).

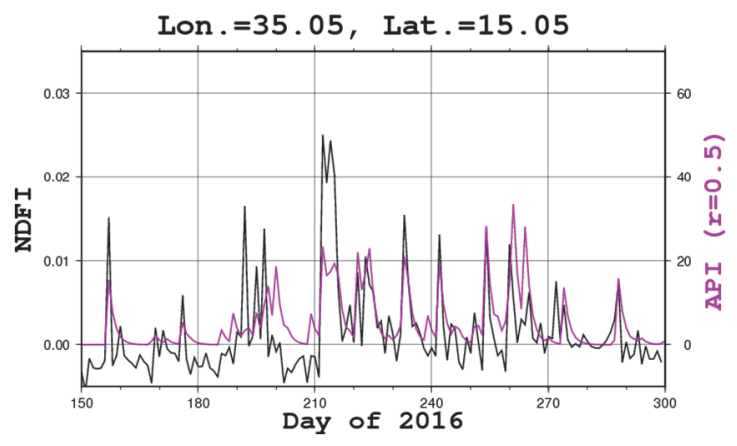

Fig.11 Daily time series of NDFI (black) and API ( $r=0.5$; purple) for 150 - 300 days in 2016 at $(35.05 \mathrm{E}, 15.05 \mathrm{~N})$.

latitudes above $60^{\circ}$ were not considered. Most regions with D-NDFI larger than 5 (Fig.9) were similar to regions with correlation coefficients of 0.3 or higher (Fig.10). As an example of a region that falls into both of these categories, Fig.11 shows the daily variations in NDFI and API $(r=0.5)$ for $150-$ 300 days of 2016 at a region in eastern Africa $(35.05 \mathrm{E}$, $15.05 \mathrm{~N})$. The increase immediately after precipitation and the decrease thereafter are in good agreement. Thus, the temporary presence of rainfall on the ground surface in arid regions eases the acquisition of the increase in NDFI because there are very few obstacles, such as forests, allowing easy observation. Conversely, some cases of sudden increases in NDFI that do not correspond to API exist need to be examined separately. 


\section{SUMMARY AND CONCLUSIONS}

We developed a global surface water map with a daily temporal resolution, and verified the correspondence of spatial distribution and temporal variation with surface water using global data. The development procedure was simplified in dividing the orbit data into grids and in managing observation times. Therefore, there is room for further improvements in the future. Although the validation of the results gave promising results for the relationship between NDFI and surface water, a detailed study of the regions is necessary to convert the time-series data of NDFI into physical quantities related to the surface water, which can be utilized for disaster management and mitigation strategies and to understand the changes in the hydrological cycle.

ACKNOWLEDGMENTS: This work was supported by JSPS KAKENHI Grant Number JK06582 "Global satellite mapping of wet surface and diversified monitoring of hydrological changes" (PI: Shinta Seto) and JST/JICA SATREPS “Advancing Co-design of Integrated Strategies with Adaptation to Climate Change" (PI: Taikan Oki). Yesterday's Earth at EORC product was provided by JAXA and University of Tokyo. The GPM L1C product was provided by NASA. We would like to thank these groups for their cooperation.

\section{REFERENCES}

1) Takeuchi, W., Mori, S. and Sawada, H.: The production and validation of surface water distribution map estimated by using AMSR-E, $18^{\text {th }}$ IIS Forum, 2009. (in Japanese)

2) Hou, A., Kakar, R. K., Neeck, S., Azarbarzin, A. A., Kumerrow, C. D., Kojima, M., Oki, R., Nakamura, K. and Iguchi, T.: The global precipitation measurement mission,
Bull. Amer. Meteor. Soc., Vol.95, pp.701-722, 2014.

3) Aires, F., Miolane, L., Prigent, C., Pham, B., Fluet-Chouinard, E., Lehner, B. and Papa, F.: A global dynamic longterm inundation extent dataset at high spatial resolution derived through downscaling of satellite observations, J. Hydromet., Vol.18, pp.1305-1325, 2017.

4) Pekel, J.-F., Cottam, A., Gorelick, N. and Belward, A. S.: High-resolution mapping of global surface water and its long-term changes, Nature, doi:10.1038/nature20584, 2016.

5) Berg, W., Bilanow, S., Chen, R., Datta, S., Draper, D., Ebrahimi, H., Farrar, S., Jones, W. L., Kroodsma, R., McKague, D., Payne, V., Wang, J., Wilheit, T. and Yang, J. X.: Intercalibration of the GPM microwave radiometer constellation, J. Atmos. Oceanic. Technol., Vol. 33, pp.2639-2654, 2016.

6) Ushio, T., Kubota, T., Shige, S., Okamoto, K., Inoue, T., Takahashi, N., Iguchi, T., Kachi, M., Oki, R., Morimoto, T. and Kawasaki, Z.: A Kalman filter approach to the Global Satellite Mapping of Precipitation (GSMaP) from combined passive microwave and infrared radiometric data, $J$. Meteor. Soc. Japan, Vol.87A, pp.137-151, 2009.

7) Takata, T., Emori, S. and Watanabe, T.: Development of the minimal advanced treatments of surface water interaction and runoff (MATSIRO), Global and Planetary Change, Vol.38, pp.209-222, 2003.

8) Yamazaki, D., Kanae, S., Kim, H. and Oki, T.: A physically based description of floodplain inundation dynamics in a global river routing model, Water Resour. Res., Vol.47, W04501, doi:10.1029/2010WR009726, 2011.

9) Maeda, T., Taniguchi, Y. and Imaoka, K.: GCOM-W1 AMSR2 Level 1R product: Dataset of brightness temperature modified using the antenna pattern matching technique, IEEE Trans. Remote Sens., Vol.54, No.2, pp.770-782, 2016.

(Received January 19, 2021) (Accepted March 31, 2021) 